\title{
Mémoires d’une Française sur les jours des Blancs à Sébastopol
}

\author{
Denis DENISOV \\ Doctorant en Histoire \\ Centre des Recherches Historiques (UMR 8558) \\ École des Hautes Études en Sciences Sociales (FR) \\ denisov.denis@ehess.fr
}

Doi :10.5077/journals/connexe.2021.e533

\section{Résumé}

Cet article consiste en la publication d'une source issue des Archives d'État de la ville de Sébastopol, accompagnée d'un commentaire préliminaire qui examine l'utilité de ce document dans le cadre de l'étude de l'intervention française dans l'ancien Empire russe. Il s'agit d'un précieux témoignage d'une locale qui présente certains épisodes de la vie de son mari, un marin français nommé Jean Lebreton. Ce dernier déserte son cuirassier durant l'intervention française et s'installe à Sébastopol. Madame Lebreton, dont le prénom nous est inconnu, décrit ses mésaventures ainsi que celles de son époux et dévoile leur tragique destin. De surcroit, cette archive contient deux lettres de son mari écrites pendant que le couple était emprisonné à Constantinople en 1921.

L'étude de ces documents semble pertinente tant dans une perspective d'histoire partagée que dans le cadre des études de genre, afin d’aborder l'épisode de la Révolution et de la Guerre civile russe.

Mots-clés : Sébastopol, ouvriers, intervention française, histoire partagée.

\begin{abstract}
This article is a publication of a source from the State Archives of the city of Sevastopol, with a preliminary commentary that discusses the relevance of this document to the study of French intervention in the former Russian Empire. It is a precious testimony of a local woman who describes some events in the life of her husband, a French sailor named Jean Lebreton. The latter deserted his cuirassier during the French intervention and settled in Sebastopol. Madame Lebreton, whose first name is unknown to us, relates her misadventures and those of her husband and reveals their tragic fate. In addition, this archive contains two letters from her husband written while the couple was imprisoned in Constantinople in 1921.

The study of these documents seems relevant both from a shared history perspective and in the scope of gender studies, in order to address the episode of the Revolution and the Russian Civil War.
\end{abstract}

Keywords: Sevastopol, workers, French intervention, Shared history. 
Dans son rapport du 15 mai 1919 sur l'évacuation des prisonnier.ère·s français·es d'Odessa, Welfelé, le commandant du torpilleur Protet, ancien supérieur d'André Marty, évoque trois marins déserteurs, « purs bolchéviques », qui accompagnaient le capitaine Jacques Sadoul et faisaient de la propagande auprès de ses compatriotes. Welfelé les soupçonnne d'être responsables de l'arrestation et du meurtre de « quatre Français ", tout en reconnaissant que cette information, rapportée par certains prisonniers français, " aurait besoin d'être contrôlée ». Il les traite de " criminels » en les opposant aux « soldats qui semblent être restés des bons français » (Masson $1982,435)^{1}$. Ici nous voulons présenter un témoignage portant sur un autre cas de marins français passés du côté des Soviétiques, mais à Sébastopol.

C'est le récit de la vie d'un certain Jean Lebreton dans l'ex-Empire russe et à Constantinople entre 1919 et 1921 . L'auteure en est sa femme, qui n'a pas laissé de signature. Il semble qu'elle était de Sébastopol, mais elle se présente comme « une Française ${ }^{2}$ dans le titre de ses mémoires, et elle est appelée " Madame Lebreton » dans les deux lettres de son mari qui constituent la partie française du texte. Ce document, conservé sous la cote ГАГС, ф. p-391, оп. 1, д. 29 (voir Figures 1 à 5) appartient au Fonds des documents sur l'histoire de la Révolution à Sébastopol, constitué dans les années 1920-1930 par Mihail Lebedev, à l'époque chef de l'antenne à Sébastopol de la Société des anciens forçats et exilés politiques (Fonds p-391 des archives d'État de la ville de Sébastopol, ГАГС) ${ }^{3}$. Ce cahier de dix feuilles (les deux feuilles de couverture ainsi que la dernière feuille sans notes ne sont pas numérotées) comprend treize pages de texte manuscrit dont dix en russe et trois en français. L'exactitude de ce récit reste à vérifier. Cependant, de nombreuses traces des marins français « bolchéviques » nous incitent à penser que cette source relate des événements réels.

1 Voir : Rapport de M. le capitaine de corvette Welfelé, commandant du Protet, Tendra, le 15 mai 1919, Service historique de la défence (SHD), MV SS A 174, Protet. Mai, juin 1919.

2 Dans le contexte donné, cela veut dire également " une femme d'un Français ", ce qui peut être comparé à " генеральша " (" générale ", c'est-à-dire "femme d’un général »). Voir : Mémoires d'une Française sur les jours des Blancs à Sébastopol, Государственный архив города Севастополя (ГАГС), ф. p-391, оп. 1, д. 29, лл. couverture, 5-6 об.

3 Il est important de souligner qu'il s'agissait d'une association qui, à la différence de l'Istpart, l'Institut d'Histoire du Parti communiste, a eu beaucoup moins d'influence institutionnelle, tant sur la carrière et la vie des témoins que sur les questions de gestion des avantages pour les vétérans des révolutions et de la Guerre civile. Cela prouve, à nos yeux, la fiabilité du présent témoignage. 
Denis DENISOV - Mémoires d'une Française sur les jours des Blancs à Sébastopol

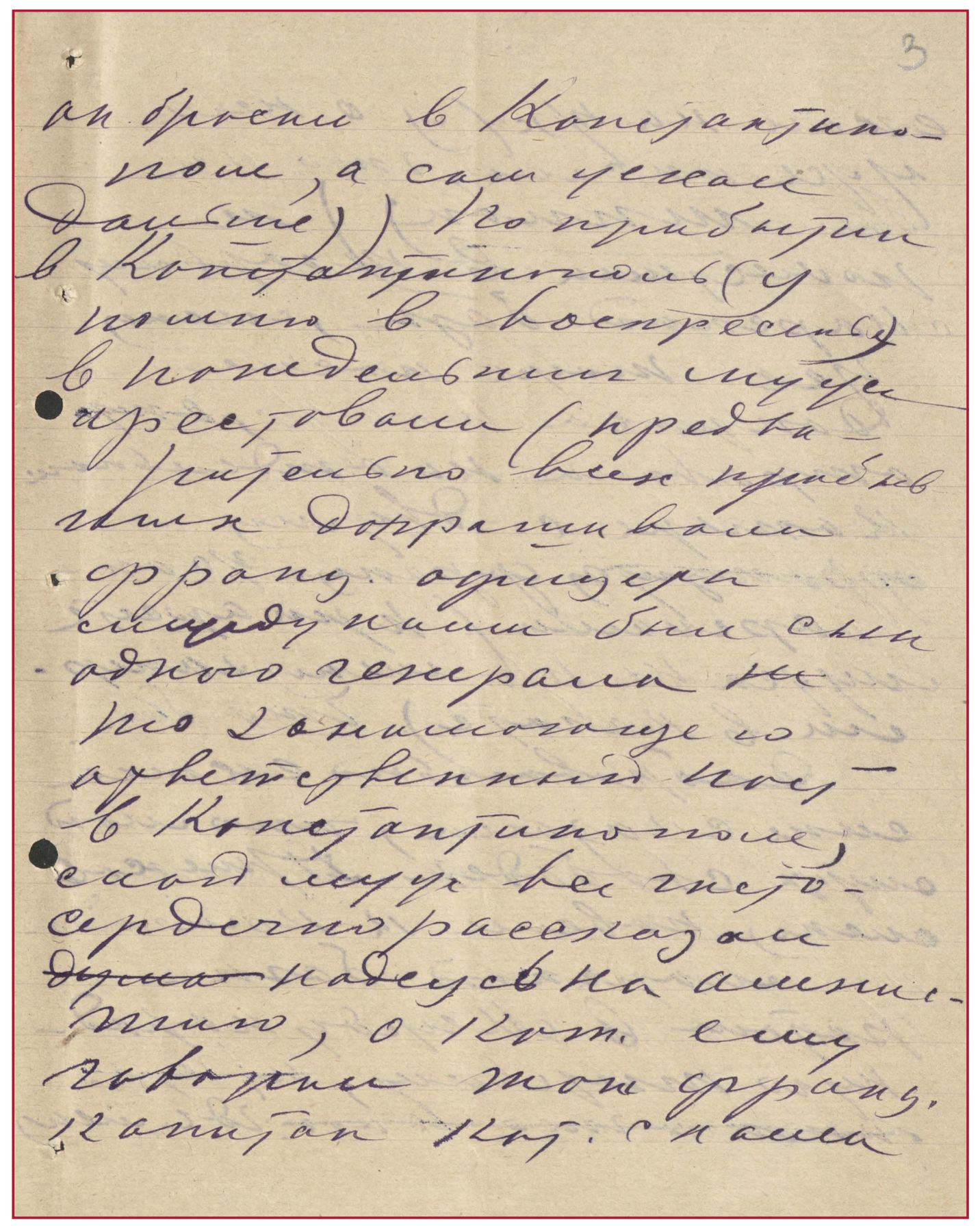

Figure 1. Page du cahier du Krympoligraftrest (ГАГС ф. p-391, оп. 1, д. 29)

CONNEXE 7| 2021 - La Guerre civile après 1917 : les échelles d'un conflit et sa représentation

$-155-$ 
Denis DENISOV - Mémoires d'une Française sur les jours des Blancs à Sébastopol

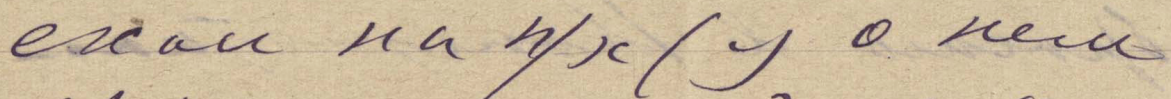

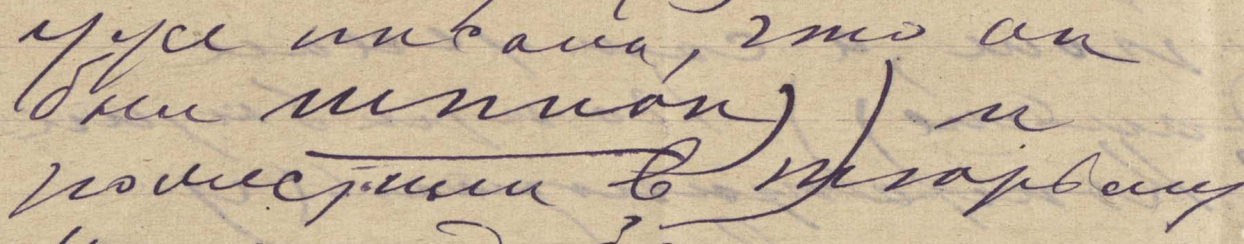

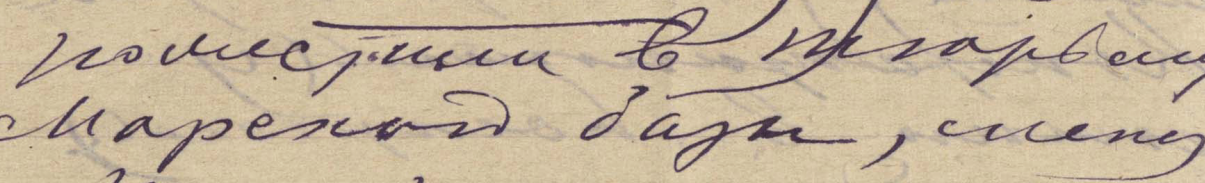
Jee nana naewe Lanjunca u $и$ a ompabuin Ha á mócubuare Lasupe $c$ Pheneng

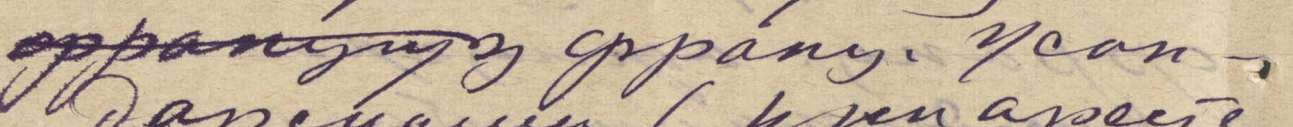
Dapenacue f tejen ajoeste

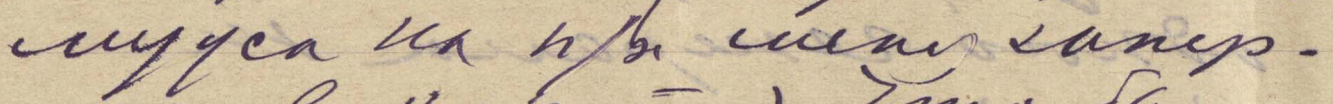
cu b kanate) ऐina for I Qadjuhnerweraca exu ellayaun, munand

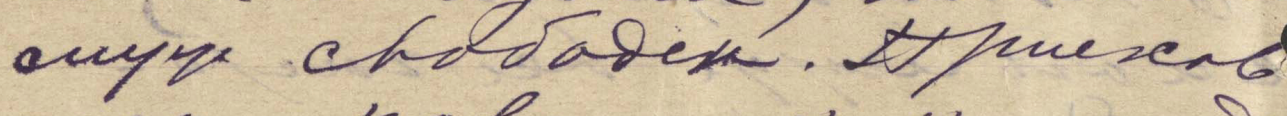
aceny nabeuck IR Kowendamy evajuenents jask pajion 6 dheyed, wapas. Hej minclace, thes

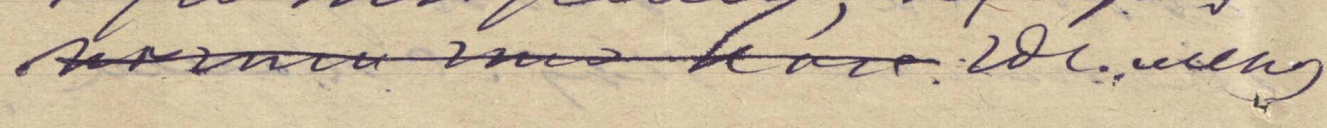

Figure 2. Page du cahier du Krympoligraftrest (ГАГС ф. p-391, оп. 1, д. 29)

CONNEXE 7 | 2021 - La Guerre civile après 1917 : les échelles d'un conflit et sa représentation

$\overline{-156-}$ 
Denis DENISOV - Mémoires d'une Française sur les jours des Blancs à Sébastopol

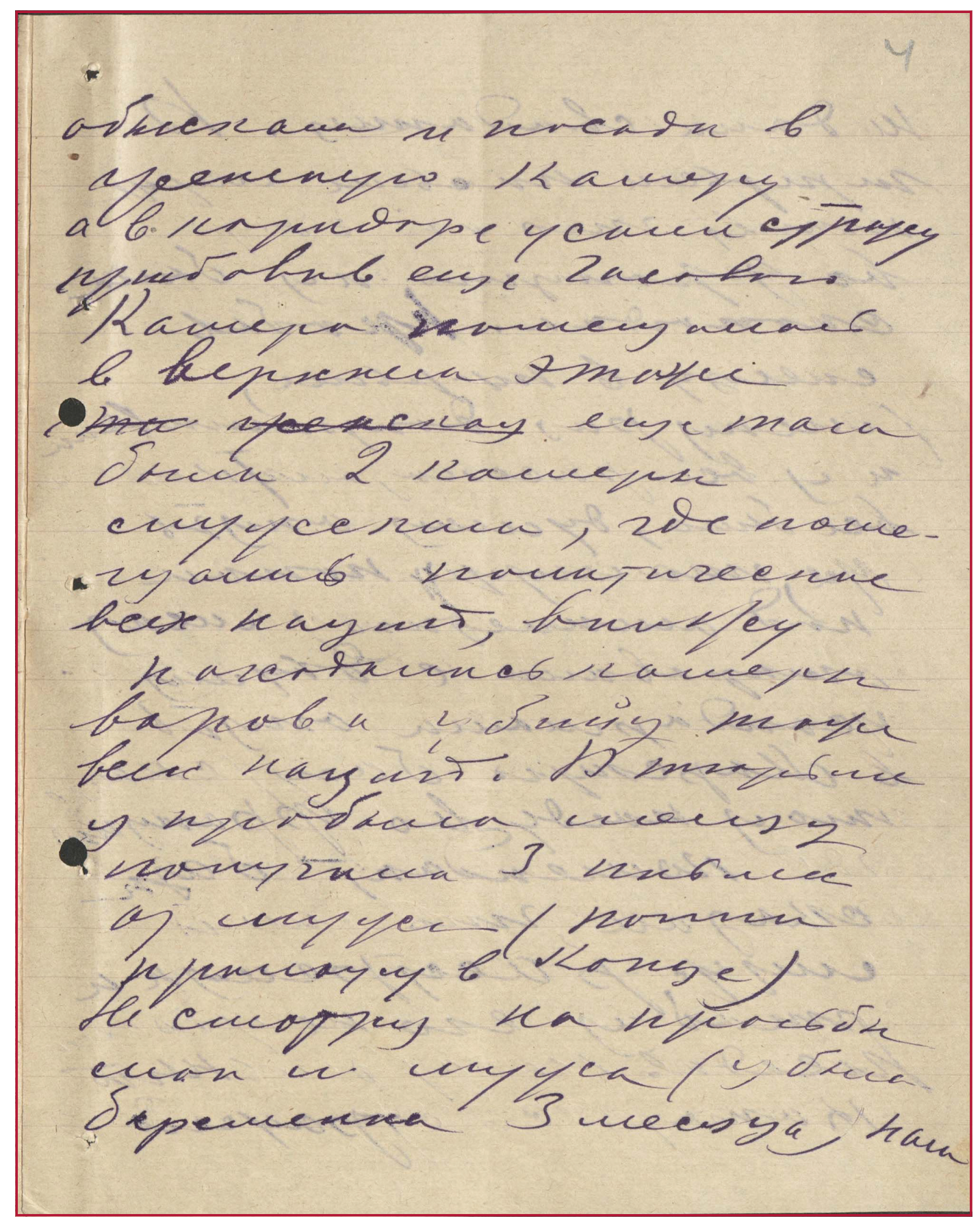

Figure 3. Page du cahier du Krympoligraftrest (ГАГС ф. p-391, оп. 1, д. 29)

CONNEXE 7 | 2021 - La Guerre civile après 1917 : les échelles d'un conflit et sa représentation

$\overline{-157-}$ 
Denis DENISOV - Mémoires d'une Française sur les jours des Blancs à Sébastopol

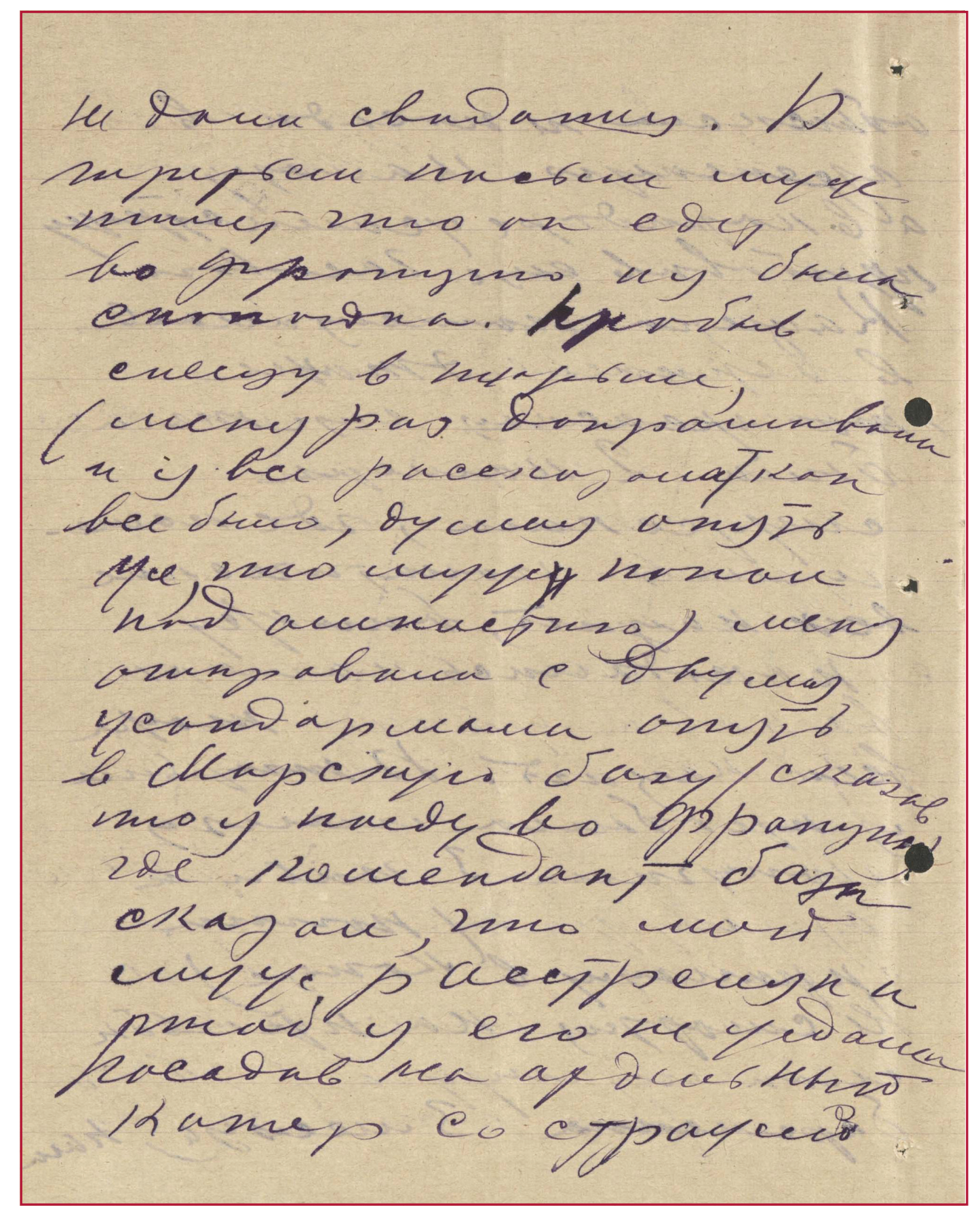

Figure 4. Page du cahier du Krympoligraftrest (ГАГС ф. p-391, оп. 1, д. 29)

CONNEXE 7| 2021 - La Guerre civile après 1917 : les échelles d'un conflit et sa représentation

$\overline{-158-}$ 
Denis DENISOV - Mémoires d'une Française sur les jours des Blancs à Sébastopol

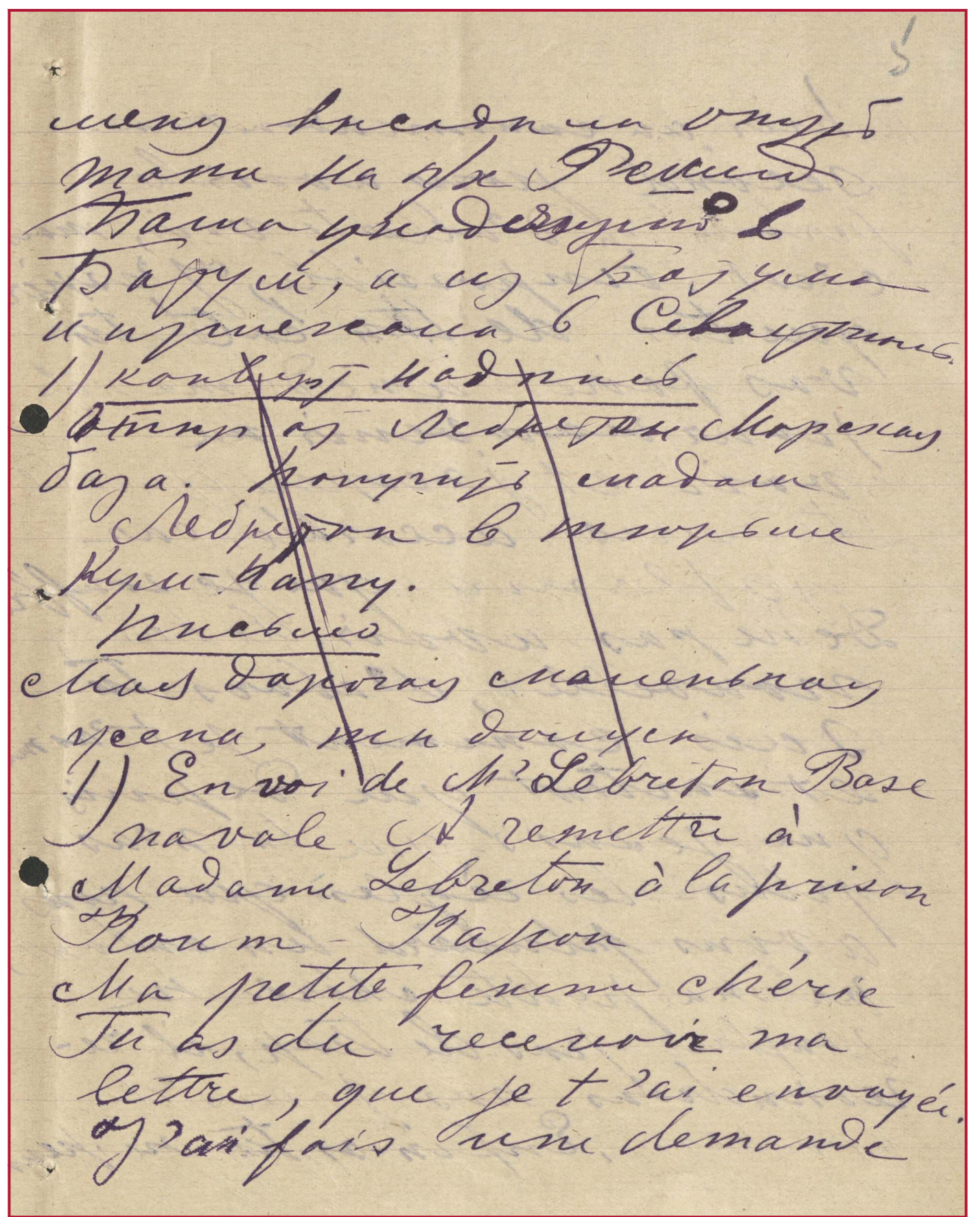

Figure 5. Page du cahier du Krympoligraftrest (ГАГС ф. p-391, оп. 1, д. 29)

CONNEXE 7| 2021 - La Guerre civile après 1917 : les échelles d'un conflit et sa représentation

$\overline{-159-}$ 
Dans un premier temps, rappelons le contexte de ces écrits. La présence française à Sébastopol dans le cadre de l'intervention militaire de l'Entente cesse suite à la révolte dans la $2^{\mathrm{e}}$ escadre qui a eu lieu les 19 et 20 avril 1919. Les deux derniers navires français quittent la rade de Sébastopol le 5 mai 1919. Ce sont les cuirassés Justice et Mirabeau. Le Mirabeau, sérieusement endommagé suite à son échouage à l'entrée dans la rade le 8 février 1919, a été pris en remorque par le Justice (Revault 1981, 216). À partir du 5 mai 1919 et jusqu’à la fin du mois de juin 1919, le pouvoir à Sébastopol fut entièrement aux mains des soviets.

Un historien local, Genadij Vaneev, dans sa chronique Sébastopol. Pages d'histoire. 1783-1983 évoque un rassemblement à l'occasion de l'ouverture à Sébastopol du Club Lénine le 13 mai 1919 où un marin français prononce un discours (Ванеев 1983, 90). On ne trouve pas d'autre confirmation par documents d'archives de l'existence d'un groupe de marins français pro-bolchéviques à Sébastopol dans l'historiographie soviétique.

Notre travail aux archives d'État de la ville de Sébastopol ${ }^{4}$ comble cette lacune, bien que d'une manière très partielle. Lors de la séance du collège technique ${ }^{5}$ de l'Arsenal, tenue le 23 mai 1919, l'ordre du jour mentionne, en son septième point, la question des « marins français travaillant aux ateliers de l'Arsenal ; de leur participation à la caisse de maladie ». Le collège prescrit aux « ouvriers français travaillant [à l'Arsenal] » de « s'inscrire au syndicat » tandis que les malades parmi eux sont à soigner à l'hôpital aux frais de l'entreprise ${ }^{6}$.

Marin du cuirassé Justice, Jean Lebreton prend la décision de rester à Sébastopol. Sa femme dit qu'il fuit son cuirassé par peur dela répression (et même de condamnation à mort) pour avoir brandi le drapeau rouge ${ }^{7}$. C'est vraisemblable car un autre récit, celui du fils du ministre de la Marine française, Jacques Raphaël-Leygues, mentionne que le 20 avril, deux marins " attachent une étoffe rouge sur une corde à linge » à bord du Justice (Raphaël-Leygues, Barré 1981, 29).

Après sa fuite, Jean Lebreton est embauché à l'Arsenal de Sébastopol en qualité d'ouvrier. Il épouse sa compagne lors de la seconde période du pouvoir soviétique en Crimée (29 avril-23 juin 1919). La cérémonie religieuse a eu lieu à l'église SaintMitrophan-de-Voronej ${ }^{8}$, située dans le quartier ouvrier Korabelnaïa storona (Чикин 2008, 561). Il est difficile de dire, si cela reflète une véritable religiosité de ce couple.

4 Je tiens à remercier les membres du personnel des Archives d'État de la ville de Sébastopol pour leur aide et bienveillance.

5 Direction de l'entreprise sous les soviets, constituée des vieux cadres dirigeants et de représentants des ouvriers.

6 ГАГС, ф. p-253, оп. 2, д. 16, лл. 348-348 об.

7 Mémoires d’une Française sur les jours des Blancs à Sébastopol, ГАГС, ф. p-391, оп. 1, д. 29, л. 1.

8 Ibid., л. 1 об.

CONNEXE 7 | 2021 - La Guerre civile après 1917 : les échelles d'un conflit et sa représentation 
En réalité, le souci pouvait être d'ordre tout à fait pratique, car même sous les soviets en 1919, les registres de l'état civil étaient encore détenus par les églises9 ${ }^{9}$. Sous les Blancs, qui ont repris la ville le 24 ou le 28 juin 1919 (ils vont rester dans la ville jusqu'à l'évacuation des troupes de Wrangel du 13-16 novembre 1920), Lebreton est arrêté pour sa propagande parmi les ouvriers. Sa femme ajoute, dans les notes finales du cahier, que c'était le capitaine français Amalric (que les époux Lebreton rencontrent presque deux ans après, en 1921, à Odessa) qui a donné l'ordre à Filatov, chef du service de Contre-espionnage des Blancs à Sébastopol, d'arrêter Jean Lebreton. Il est libéré des geôles du service de contre-espionnage des Blancs grâce à une rançon considérable (18 000 roubles) donnée par sa femme aux officiers corrompus chargés de cette affaire. La somme a été rassemblée par le syndicat des métallurgistes. Les tentatives de Madame Lebreton auprès du contre-espionnage pour libérer son mari lui ont coûté sa place à l'Arsenal ${ }^{10}$. Après sa libération, qui a eu lieu au plus tard à la fin de 1919, Lebreton s’installe avec sa femme à Djankoï, puis à Melitopol. Dans ces deux villes, il travaille comme ouvrier d'usine ${ }^{11}$.

Les époux déménagent à Odessa, après la prise de Melitopol par les Rouges le 30 octobre 1920. Il faut prendre en compte que la plupart des mutins de la mer Noire ont été amnistiés en 1920 (Raphaël-Leygues, Barré 1981, 143). Le couple a probablement pris la décision d'émigrer après avoir lu ces nouvelles dans la presse soviétique lors du procès des mutins de la mer Noire, mais sans doute aussi pour fuir la crise économique (blocus des républiques soviétiques, famine en Crimée) qui frappait le pays à l'époque. Quoi qu'il en soit, en mars 1921, ils prennent le bateau à vapeur Réchide Pacha pour Constantinople, suite aux promesses d'amnistie que le capitaine français qui les accompagnait leur avait faites. On peut supposer qu'il s'agissait du capitaine Amalric. Selon Madame Lebreton, Amalric remplissait une mission d'espionnage à Odessa où il résidait et était marié à une Russe. Amalric pouvait également avoir participé à l'évacuation des Français et des Françaises, comme Welfelée ${ }^{12}$.

À son arrivée à Constantinople, Jean Lebreton est interrogé par le capitaine Jean (ou Eugène) Fernand Robert, puis il est arrêté par le capitaine Anselm (sic) et transféré dans la prison de la base navale de Constantinople. Le père de cet « Anselm

9 Registres détat civil de Sébastopol, ГАГС, ф. 30, оп. 1.

10 Comme les archives de la Marine russe en témoignent, des femmes ont été fréquemment embauchées à la voilerie comme Evdokija Kozlenko ou Matrëna Kušpet. Voir : Российский государственный архив Военно-морского флота (РГА ВМФ), ф. 920, оп. 2, дд. 1060, 1666. La voilerie a été attachée à l’Arsenal suite à sa séparation du Port militaire à la fin de 1918. Voir : Ordre du chef de l'arrière du 20 février $1919 N^{\circ} 3$, ГАГС, ф. p-253, оп. 1, д. 1, л. 28 об. Il y avait aussi des femmes parmi le personnel administratif comme Melentina Jakovleva. Voir : РГА ВМФ, ф. 920, оп. 2, д. 1977.

11 Mémoires d’une Française sur les jours des Blancs à Sébastopol, ГАГС, ф. p-391, оп. 1, д. 29, лл. 1-2.

12 Ibid., л. 7. 
occupait un poste important à Constantinople $»^{13}$. Après quelques tentatives pour voir son mari, Madame Lebreton est emprisonnée elle aussi et transférée dans la même prison, mais dans le quartier des femmes. Jean Lebreton envoie alors trois lettres à sa femme dont deux, sauf la troisième, où Monsieur Lebreton parlait de partir en France ${ }^{14}$, sont reproduites en français dans le texte des Mémoires. Après un certain temps, elle est libérée, mais elle apprend par le biais du commandant de la base navale que son mari a été fusillé ${ }^{15}$. Elle reprend le même bateau à vapeur Réchide Pacha pour Batoumi, d'où elle repart pour Sébastopol. Selon Madame Lebreton, Amalric n'a pas voulu enregistrer son mariage. Au moment de son arrestation Madame Lebreton était enceinte depuis déjà trois mois. La suite de cette histoire tragique, qui comprend désormais le destin de l'enfant dont elle était enceinte, est malheureusement inconnue.

Certains détails donnent l'impression que le récit est fiable. L'identité de Jean Lebreton est toutefois difficile à confirmer, d'autant plus que sa première lettre est signée «Fernand ». Cela s'explique probablement par un souci de dissimuler son identité (Raphaël-Leygues, Barré 1981, 29), mais Fernand peut également être son deuxième prénom ou son nom d'usage. De toute façon, nous n'avons trouvé de traces ni d'un Jean Lebreton ni d'un Fernand Lebreton sur le site « Mémoire des Hommes » ${ }^{\mathbf{1 6}}$ qui recense les combattants français de la Première Guerre mondiale.

Il serait pourtant possible d'effectuer des recherches dans les fonds du Service Historique dela Défense, notamment dansles fonds dela basenavale deConstantinople pour l'année 1921. Une autre option serait de chercher dans les rapports des renseignements ( $2^{\mathrm{e}}$ bureau) provenant d'Odessa en 1921 puisque Amalric, l'officier en question, aurait été chargé de mission d'espionnage selon Madame Lebreton. On pourrait encore explorer les archives odessites au sujet du " centre d'évacuation ». Les documents concernant l'identité de Madame Lebreton et de son mariage ne sont pas disponibles. Les registres d'état civil de l'église Saint-Mitrophan-de-Voronej sont absents des Archives d'État de la ville de Sébastopol ${ }^{17}$. Admettons la discrétion de cette femme inconnue : Madame Lebreton parle très peu d'elle-même. Et pourtant c'est un récit de soi.

La dernière partie du texte, bien que non signée, est écrite par la même personne : car si les encres utilisées diffèrent, l'écriture est identique. Ainsi, l'autrice complète le récit, notamment en inscrivant les noms des officiers français responsables du tragique destin des époux Lebreton. Dans cette notice, on constate que Jean Lebreton

13 Cela doit être le général d’Anselm. On peut supposer que le grade comme la particule aristocratique ont été oubliés. Voir : Ibid., л. 6 об.

14 Ibid., л. 4 об.

15 À ce jour, seule cette déclaration du capitaine de la base navale soutient cette hypothèse.

16 Site web de la Mémoire des Hommes

17 Registres d'état civil de Sébastopol, ГАГС, ф. 30, оп. 1.

CONNEXE 7 | 2021 - La Guerre civile après 1917 : les échelles d'un conflit et sa représentation 
est appelé « camarade Lebreton ». De surcroît, Madame Lebreton corrige a posteriori son récit : le capitaine du centre d'évacuation (probablement le capitaine Amalric) ne serait arrivé à Odessa qu'à la fin du mois de mars, voire au début du mois d'avril $1921^{18}$.

Ces mémoires ne sont pas composées avant 1923. Le dossier du «дело 29 » porte la date 1924, mais cela semble faire référence au calendrier de l'année 1924 qu'on trouve au dos du cahier d'écolier, avec une table de multiplication et une table de correspondance des mesures russes et métriques ${ }^{19}$, mais le cahier peut avoir été fabriqué en 1923 pour l'année scolaire 1923-1924.

Le cahier présente en soi un intérêt particulier grâce à sa couverture dont nous reproduisons le front (voir Figure 6). C'est une très belle source iconographique. Le cahier du Krympoligraftrest (trust polygraphique de Crimée) est illustré d'une image composée de trois éléments : le portait du président de l'Internationale communiste Grigori Zinoviev en haut à droite ; un paysage allégorique du socialisme soviétique en haut à gauche ; une nature morte représentant les moyens de production manuels et intellectuels sur un pupitre en bas à droite. Le paysage socialiste est assez classique : il représente la perspective d'un chemin bordé de lignes télégraphiques qui passent par des champs et qui guident le spectateur jusqu'à l'usine à l'horizon, sur le fond d'un soleil levant. Le portrait de Zinoviev et les moyens de production sont chargés d'un symbolisme révolutionnaire plus complexe, révélant de hautes ambitions. D'ailleurs, on trouve directement sous le portrait de Zinoviev (encadré par des épis de blé) le symbole soviétique, la faucille et le marteau. Le matériel scolaire (fournitures de dessin, encrier, stylo, plume, livres, globe) est situé au-dessous de la faucille et du marteau, donnant ainsi une double perspective. D'un côté, ils peuvent être regardés du point de vue individuel d'un·e élève qui doit faire ses études pour devenir un·e ouvrier.ère non seulement instruit.e, mais aussi cultivé.e. De l'autre côté, cela peut être vu comme une perspective historique, par le passage progressif du travail manuel au travail intellectuel. Pourtant, il semble qu'à l'époque, la première interprétation dominait, ce que le paysage et l'orientation des perspectives des deux images confirment (de l'école au travail pour un·e élève, du paysage agraire au site industriel pour la société). Il est intéressant de noter que le globe (outil pédagogique par excellence sur l'image, avec les livres) s'élève au même niveau que la faucille et le marteau. Par rapport au spectateur, le globe se situe devant la faucille et le marteau. Son orientation (le spectateur voit son hémisphère occidentale) n'est pas un hasard. C'est le symbole des espoirs d'une révolution mondiale. Il est donc très logiquement accompagné par le portait du président de l'Internationale communiste, Zinoviev. Un autre élément important de cette image va dans le même sens. C'est une citation de l'Internationale des enfants de Vasilij Knjazev : « Nous sommes des enfants du

18 Mémoires d’une Française sur les jours des Blancs à Sébastopol, ГАГС, ф. р. 391, оп. 1, д. 29, лл. 6 об.-7. 19 Ibid., feuille sans numéro.

CONNEXE 7 | 2021 - La Guerre civile après 1917 : les échelles d'un conflit et sa représentation 
peuple libre, les fleurs de la commune du Travail » (Лурье, Сенькина 1920, 240$241)^{20}$.

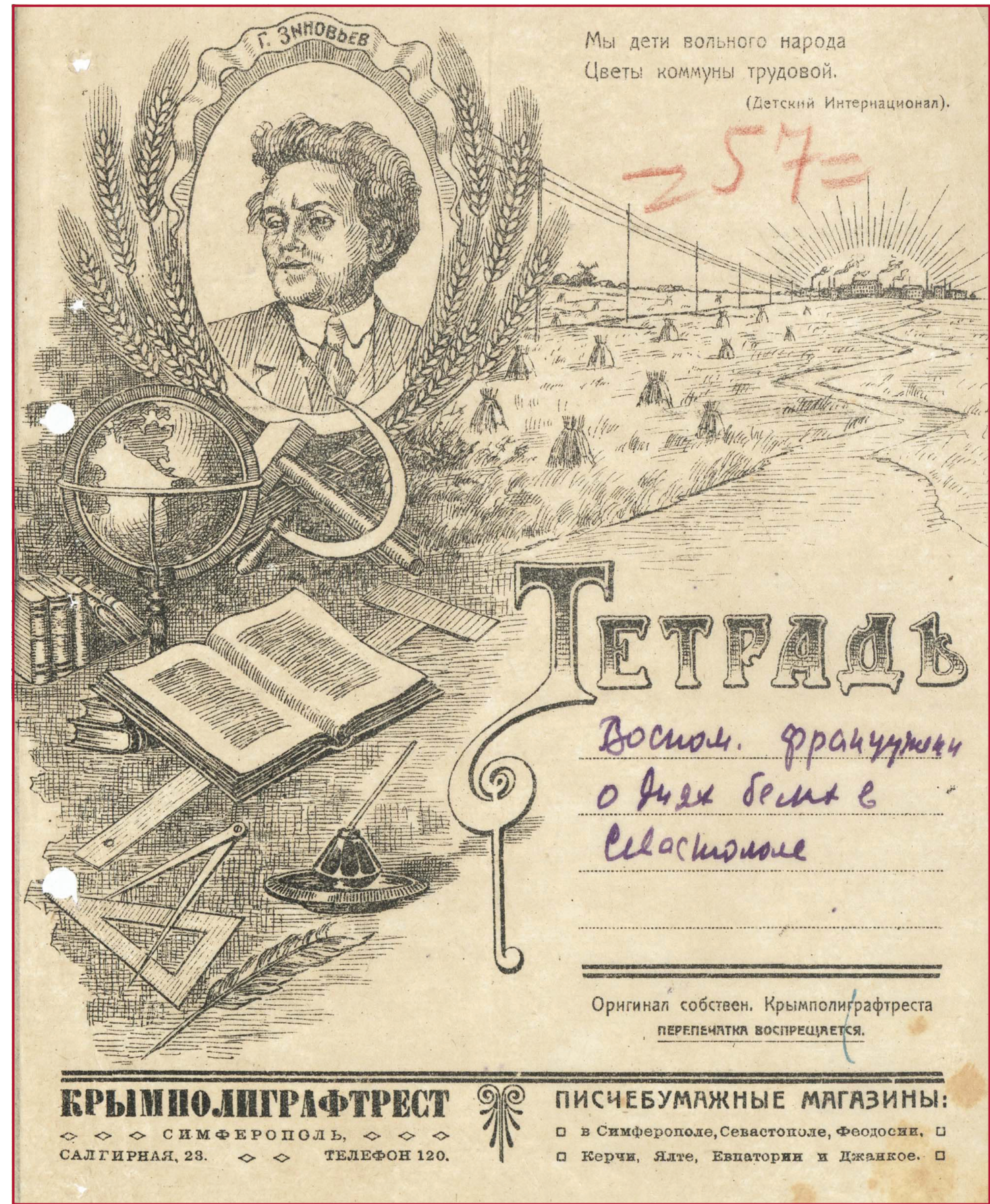

Figure 6. Couverture du cahier du Krympoligraftrest (ГАГС ф. p-391, оп. 1, д. 29).

20 Ibid., feuille sans numéro.

CONNEXE 7 | 2021 - La Guerre civile après 1917 : les échelles d'un conflit et sa représentation 
Cette source aide à comprendre une question très spécifique, importante pour étudier l'Intervention française à Sébastopol : comment les marins et soldats français d'un côté, et des ouvrier-ère-s locaux·les de l'autre, pouvaient surmonter les barrières linguistiques. Cette femme russe maittrisait le français, ce qui supposerait soit qu'elle fût issue d'une famille francophone et donc privilégiée soit, ce qui revient largement au même, qu'elle eût étudié au lycée (gymnase) ${ }^{21}$. Néanmoins, son usage de sa langue maternelle incline à écarter cette hypothèse. Dès la première page du cahier, elle fait une faute de russe typique des milieux populaires de l'Empire en écrivant «бомбандировка » à la place de « бомбардировка » (du français « bombardement ») ${ }^{22}$. Deplus, on sait qu'elle travaillaitàl'Arsenal. Sans êtreforcément travailleuse manuelle, elle pouvait au plus s'acquitter de tâches administratives, ce que lui permettait sa connaissance de la lecture et de l'écriture ${ }^{23}$. Sauf à supposer qu'elle se soit intéressée à la langue française avant le début de l'Intervention et indépendamment de son milieu, elle a plus que probablement appris le français en communiquant avec son bien-aimé devenu son mari. En effet, Jean Lebreton écrivait à sa femme en français depuis la prison de Constantinople après deux ans de mariage, ce qui signifie qu'elle comprenait le français alors que lui n'écrivait pas en russe. Certaines erreurs typiques des Russes débutant l'apprentissage du français ( « commendant en second ${ }^{24}$ est écrit comme « комендант », ou l'infinitif utilisé à la place du participe passé25) prouvent d'ailleurs que l'écriture des lettres dans cette langue n'était pas encore totalement naturelle. Il est intéressant de noter que Madame Lebreton avait commencé à traduire la première lettre en russe mais qu'elle a rayé les premières lignes pour finalement reproduire les deux lettres de son mari en langue originale. Était-ce dans le but d'éviter de potentielles erreurs de traduction ou par souci d'exactitude?

21 On ne peut pas exclure complètement cette version car les archives de la Marine russe à Saint-Pétersbourg gardent des dossiers des ouvriers « anciens nobles » comme Semen Nikolaenkov et Aleksandr Klimentov. Voir : РГА ВMФ, 920 , Оп. 2, дд. 1282, 1673. Cela reste pourtant peu probable.

22 Mémoires d’une Française sur les jours des Blancs à Sébastopol, ГАГС, ф. p-391, оп. 1, д. 29, л. 1.

23 Alors que l'illettrisme était majoritaire parmi les sébastopoliennes en 1897 (60,97 \%) et à l'époque de l'enfance de Mme Lebreton entre $45 \%$ (en 1908) et 40 \% (1912) d'enfants dans la ville ne fréquentaient pas l'école (Тройницкий 1904, 29 ; Новикова 2021, 675-676).

24 Mémoires d'une Française sur les jours des Blancs à Sébastopol, ГАГС, ф. p-391, оп. 1, д. 29, л. 5 об.

25 Ibid., л. 6 об. 
Cette source s’inscrit très logiquement dans l'histoire croisée. Elle ressort aussi de l'histoire du genre, car il s'agit du récit de soi d'une femme qui nous laisse des remarques, mais aussi des non-dits très éloquents (son identité, l'histoire de son enfant). Elle participe à la relativisation des approches qui privilégient les récits de soi des dominant.e.s (bien que renversé.e·s par les révolutions de 1917), majoritaires dans les écrits biographiques et prosopographiques de la Guerre civile dans l'ancien Empire russe. Dans cette perspective, elle servira, probablement, à une réévaluation du « complot » révolutionnaire d'André Marty, notamment concernant son plan de rejoindre, avec son navire, les rangs des Soviétiques. Était-ce juste une manifestation extrême d'une crise individuelle isolée (Masson 1982, 369-415) ou le reflet d'un sentiment de fraternité, humaine et/ou politique, avec les locaux ? Après avoir donné nos interprétations préliminaires, nous avons le plaisir de présenter ci-dessous la publication des Mémoires d'une Française sur les jours des Blancs à Sébastopol dans leur langue et orthographe originales.

\section{Воспом.[инания] француже[н]ки о днях белых в Севастополе} [лист 1]

Как иввестно в 19 году в Севастополе нах.[одилась] франц. [узская] Эскадра. На дредноуте [«]Жюстис[»] служил матрос Жан Лебретон. Когда начались волнения и протесты против бомбандировки Севастополя Лебретон, зато что он поднял красное знамя, должен был быть расстрелян, но бежал с корабля[,] пробрал[ся] в Инкерман к Красным войскам[.] По уходе французской эскадры он поступил в Севморзавод в Сл.[есарно-] сб.[орочную] мастерскую, когда же вновь пришли белые, мой муж (венчались мы

[л. 1 оборот]

в Митрофаниевской церкви) был арестован за пропаганду среди рабочих и посажен в Контр-разведку[.] Благодаря же взятке в 18тыс. (данные мне профсоюза Тов. [арищем] Шевченко) мой муж был выпущен. Предварительно же во время его ареста к нач. Контрравведки ходила делегация от рабочих сл.[есарно] сл. маст.[ерской] ; потом ходил туда же Тов.[арищ] Шевченко[,] чтобы взять моего мужа на поруки безрезультатно. Когда я отдала деньги моего мужа освободили через два дня.

[л. 2]

Между прочим[,] меня уволили со службы ; я служила в Севморзаводе, за то, что я хлопотала за мужа и[,] конечно[,] не могла исправно посещать службу .

После освобождения мы уехали в Джанкой, потом Мелитополь где дождались наступления красных войск (Мы нарочно уехали из Севастополя, чтобы скорее дождаться прихода Советской власти) [.] 
Из Мелитополя (в Джанкое и Мелитополе муж работал на заводе в Дажнкое не помню, а в Мелитополе на заводе бр. [атьев] Фабрик) нас[,] к[а]к иностран. [ных.]

[л. 2 об.]

подданных[,] отправили в одессу для следования во Францию, из Одессы мы с друпими иностранцами на турецком п/ ${ }^{26}$ Решид Паша в марте 1921 года отправились в Константинополь[.] Между прочим[,] на п/х нах. [одился] капитан франц.[узской] службы, специально посланный в Россию для шпионажа (можно справиться о его фамилии в Одесск.[ом] Эвакопункте[,] он записан наверное Там в конце марта 1921 года[,] к[а]к эвакуированный иностранец (он был женат на русской, кот.[орую]

[л. 3]

он бросил в Константинополе, а сам уехал дальше)) [.] По прибытии в Константинополь (я помню в воскресенье) в понедельник мужа арестовали (предварительно всех прибывших допрашивали франц . [узские] офицеры[,] между прочим[,] был сын одного генерала не то Занимаюего ответственный пост в Константинополе, мой муж все чистосердечно рассказал[,] дма надеясь на амнистию, о кот.[орой] ему говорил тот франц. [узский] капитан кот.[орый] с нами

[л. 3 об.]

ехал на п/х (я о нем уже писала, что он был шпион)) и поместили в тюрьму Морской базы, меня же тоже после допроса и на п/х, атр от[п]равили на отдельном катере с двумя франц. [узскими] жандармами (при аресте мужа на п/х меня заперли в каюте) чтобы я добровольно ехала[.] Мне сказали, что мой муж свободен. Приехав[,] меня повели к коменданту морской базы[,] потом в Международную тюрьму ${ }^{27}$ и (через почти что час. где меня

[л. 4 ]

обыскали и посадили в женскую камеру [, ] а в коридоре усиля стражу [, ] прибавив ещё часового[.]

Камера помещалась в верхнем этаже а бая [,] еще там были 2 камеры мужские, где помещались политические всех наций, внизу находились камеры воров и убийц всех тоже наций. В тюрьме я пробыла месяц[,] получила 3 письма от мужа (копии приложу в конце) [.] не смотря на просьбы мои и мужа (я была беременна 3 месяца) нам

[л. 4 об.]

26 Abréviation habituelle du bateau-vapeur en russe («Пароход»).

27 Dans le contexte, nous supposons que cela veut dire une prison subordonnée au Commandement des forces d'occupation de Constantinople et non aux autorités turques. 
не дали свидания. В третьем письме муж пишет, что он едет во Францию, и я была спокойна. Пробыв месяц в тюрьме, (меня раз допрашивали и я все рассказала[,] как всё было, думая опять же, что мужу попал под амнистию) меня отправили с двумя жандармами опять в Морскую базу (сказав[,] что я поеду во Францию) [,] где комендант базы сказал, что мой муж расстрелян и чтоб я его не ждала и[,] посадив на отдельный катер со стражей[,]

$[\pi$. 5 ]

меня высадили опять таки на п/х Решид Паша[,] уходящий в Батум, а из Батума я приехала в Севастополь.

1) Конверт Надпиеь

Отпр. [авлено] от лебретон Морская база. Получить мадам Лебретон в тюрьме Kум-Kany.

\#исьмо

Mоя доротая маленькая жена, ты должн

\section{1) En voi ${ }^{28}$ de $M^{r}$ Lebreton Base navale[.] A remettre à Madame Lebreton à la prison Koum-Kapou}

Ma petite femme chérie[.] Tu as du recevoir ma lettre, que je t'ai envoyée. J'ai fais une demande

[л. 5 об. $]$

hier au commendant en second pour avoir lu permition d'aller te voir, mais c'est impossible, j'espère qui toi de ton coté tu vas faire une demande pour vena venir me voir et j'espère qu'elle te seras accordée, car je t'assure que je souffre De ne pas avoir de tes nouvelles, $d^{\prime}$ abord tu sais comment je t'aime et surtout que tu $\mathrm{n}^{\prime}$ as plus tes règles que nous avons plutard un enfant ${ }^{29}$, va ma petite chérie ne souffre pas de trap, il reviendrons nos jours de bonheur. Enfin si tu ne peux

[л. 6]

pas me voir écrie moi surtout chaque jour si celui est possible et moi aussi je le ferai de mon côté. Si tu peux fait envoyé du papier à lettre une serviette et le linge sale je pourrais le laver. Je te quitte en t'envoyant la plus doux baiser de ton petit mari pour la vie Fernand[.] Voici mon adresse à la prison base navale de Constantinople.

28 Lire : " envoi ».

29 C'était une méthode populaire de calcul de la date d'accouchement (Мухина, Пушкарева 2012, 162).

CONNEXE 7 | 2021 - La Guerre civile après 1917 : les échelles d'un conflit et sa représentation 


\section{2) A madame Lebreton à la prison de Koum-Kapou lettre matelat ${ }^{30}$ à} la base Navale.

Ma petite femme, Deux mots pour te faire savoir

[л. 6 об. $]$

que je suis en bonne santé la nourriture n'est pas trop mauvaise seuleument ce que je souffre c'est d'être séparer de toi nous qui n'avons jamais été séparé, j'espère tu va faire tout ton possible pour venir me n voir[.] Enfin si tu ne pense pas écrie moi un peu pour savoir de tes nouvelles. Un gras baiser de ton petit mari que t'aime pour la vie.

Капитан[,] допрашивавший т. [оварища] Лебретона[,] Жен Фернанд Роберт и арестовавший капитан Ансельм. Отец капитана Ансельма занимал ответственный пост в Константинополе.

[л. 7]

Французсктй капитан Амальрик посил приказал Филатову [, ] начальнику Контр-разведки Севасто[поля,] арестовать т.[оварища] Лебретона.

Амальрик не пожелал зарегистрировать брак Лебретона.

в 1921г. в начале апреля или в конце марта Капитан французской службы был послан специально искать [rayé illisible] ушедших с французских кораблей[,] уговаривать мужа Лебретон ехать во Францию[,] якобы получивших амнистию. Лебретон был арестован по указанию этого капитана[.] везли нас с Эвакопункта на пароходе „Решид Паша.”

30 Lire : « matelot ». 


\section{Références bibliographiques}

Masson, Philippe. 1982. La Marine Française et la mer Noire (1918-1919). Paris : Publications de la Sorbonne.

Raphäl-Leygues, Jacques, Barré, Jean-Luc. 1981. Les mutins de la mer Noire. Avril 1919 : des marins français se révoltent. Paris : Plon.

Revault, Hélène. 1981. Le drame du cuirassé Mirabeau en Mer Noire, février-mai 1919. Angers : Imprimerie S.E.T.I.G. J. PALUSSIER.

Ванеев, Геннадий. 1983. Севастополь. Страницы истории. 1783-1983. Симферополь : « Таврия ».

Лурье, М. Л., и Сенькина, А. А. 2020. “ Детские “Интернационалы” 1920-х годов (комментарий к пьесе В. П. Правдухина “Школьный учитель, или Трудовая артель”) ». In Commentarii litterarum. Ad honorem viri doctissimi Valentini Golovin. C. 229-251. Санкт-Петербург : « Пушкинский Дом ».

Мухина, 3. 3., и Пушкарева Н. Л. 2012. « Дородовой период и роды в жизни крестьянки пореформенной России (преимущественно центральных губерний) ». Via in tempore. История. Политология 126 : С. 160-167.

Новикова, Е. В. 2021. « Развитие народного образования ». In История Севастополя в трех тотах. Том II. Севастополь в эпоху Российской империи. Конец XVIII века - 1917 ә. éd. Захаров, В. Н., Прокопенков, В. Н., 664-677. Москва : Издательство « ИстЛит ».

Тройницкий, Н. А., ред. 1904. Первая Всеобщая перепись населения Российской империи 1897 г. Tом XLI. Таврическая губерния. Санкт-Петербург : издание Центрального статистического комитета Министерства внутренних дел.

Чикин, Аркадий. 2008. Севастополь. Историко-литературный справочник. Севастополь : « Вебер ».

Open Access Publications - Bibliothèque de l'Université de Genève

Creative Commons Licence 4.0

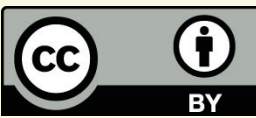

